www.jmscr.igmpublication.org Impact Factor 5.244

Index Copernicus Value: 5.88 ISSN (e)-2347-176x ISSN (p) 2455-0450 crossref DOI:_http://dx.doi.org/10.18535/jmscr/v4i6.79

\author{
Journal Of Medical Science And Clinical Research \\ IGM Publication \\ An official Publication of IGM Publication
}

\title{
Sex Determination from the Clavicle
}

\author{
Authors \\ Dr Gopal Bagal ${ }^{1}$, Dr Savita Takale ${ }^{2}$ \\ ${ }^{1}$ Associate Professor, ACPM Medical College, Dhule, Maharashtra, India-424001 \\ ${ }^{2}$ Associate Professor, CSMSS, Ayurvedic Medical College, Aurangabad, Maharashtra, India-434000 \\ Corresponding Author \\ Dr Gopal Bagal \\ Associate Professor, Department of Anatomy, \\ ACPM Medical College, Sakri Road, Dhule, Maharashtra, India-424001 \\ Email:drgopalbagal@gmail.com
}

\begin{abstract}
Identification of sex from unidentified human skeleton remains is a challenge for anthropologists and forensic investigators. Determination of sex is relatively easy if the entire skeleton is available for examination. Even when skull and pelvis, the most reliable bones for sex determination are available not more than $98 \%$ of accuracy can be achieved in identifying the sex. Often in medicolegal cases it is expected to determine sex from isolated long bones or their fragments from the crime site in order to establish a possible identity. Various methods to do this on different bones of human skeleton have been extensively studied.

Different level of accuracy for sex determination using clavicle have been reported in various studies and on the other hand, anthropometric dimensions of different bones are unique in each race and geographic region. The purpose of this study was to find out an easy formula for determination of sex from unknown clavicle and to know about comparative differences between the right and left clavicle of male and female.

KEYWORDS: Clavicle, Clavicular length, Mid clavicular circumference, Demarcating point, Sex determination
\end{abstract}

\section{INTRODUCTION}

The human clavicle is described as a modified long bone. It has a shaft and two ends that are sternal and acromial ends. The shaft is generally curved with convexity forwards in its medial two third and concavity forwards in its lateral third. The clavicle is thicker and more curved in manual workers and its ridges for muscular attachments are better marked ${ }^{(1)}$. Clavicle fracture is more common and occurs more frequently $(80-85 \%)$ at the junction of medial two third and lateral one third $^{(2)}$.
Skeleton plays a significant role in various sciences like medicine, forensic sciences and anthropology. Estimation of sex, age, race, stature by skeleton and the presence of disease is discovered by Krogman and Iscan ${ }^{(3)}$.They stated that record of organic evolution is largely written by the hard parts of the body recognisable even after many years after death. Estimation of sex of deceased from its skeleton is not difficult task when a complete or an almost complete skeleton is available for examination ${ }^{(4)}$. Krogman (1962) obtaind an accuracy of $95 \%$ with pelvis and $98 \%$ 
when pelvis and skull were available. However, it become difficult to determine the sex of deceased if a single bone or a few bones are available. This is further complicated by racial differences that exist in the characters and measurements of bones including clavicle.

For determination of sex of clavicle, various parameters including length, weight, mid clavicular circumference, cortical index and volume have been studied by various workers. Terry (1932), Olivier (1951), and Jit and Singh (1966) observed that mid clavicular circumference was good parameter in identification of the sex of the clavicle. Mid clavicular circumference of clavicle is the most reliable indicator of sex; a combination of this measurement with weight and length yields better rsults ${ }^{(5)}$. Thats why in this study we used length and mid clavicular circumference of the clavicle to determine the sex of an individual in Marathwada region.

\section{MATERIAL AND METHOD}

The present study was conducted on 120 clavicles (60-male \& 60-female) in the Department of Anatomy. These bones were collected from the Department of Anatomy as well as from the $1^{\text {st }}$ and $2^{\text {nd }}$ year medical students. Two measurements were taken. These measurements were taken using the digital vernier caliper \& measuring tape. All readings were taken 3 times by same person to avoid interobserver error. The clavicle with congenital or acquired bone abnormality were excluded.

The maximum length of the clavicle i.e. distance between the medial and lateral end of the clavicle was measured and recorded in mm with the help of vernier caliper. Simillarly, the mid point of the clavicle was determined and mid clavicular circumference was measured at that point with the help of measuring tape and recorded in $\mathrm{mm}$. Then the data was analysed to find out the mean of the length and the mid shaft circumference of right and left clavicle in both sexes.After that demarcating points were calculated for the length and mid clavicular circumference of right and left clavicles in both sexes.

Demarcating point: Demarcating point is the reading above that no female bone was found and below that reading no male bone was found ${ }^{(6)}$.

\section{RESULTS}

The maximum length and mid clavicular circumference of clavicles were measured in 120 clavicles (60 male \& 60 female) of both sides.

\section{Length}

\section{Right Clavicle}

The length of male right clavicles varies from 123 $-158 \mathrm{~mm}$. with a mean of $138 \mathrm{~mm}$ where as that of female ranges from $116-145 \mathrm{~mm}$ with a mean of $120 \mathrm{~mm}$. No female clavicle in this series has been found to have length more than $145 \mathrm{~mm}$. Simillarly no male clavicle has been found to have length less than $123 \mathrm{~mm}$.

\section{Left Clavicle}

The length of male left clavicles varies from 118 $160 \mathrm{~mm}$. with a mean of $140 \mathrm{~mm}$ where as that of female ranges from $111-143 \mathrm{~mm}$ with a mean of $123 \mathrm{~mm}$. No female clavicle in this series has been found to have length more than $143 \mathrm{~mm}$. Simillarly no male clavicle has been found to have length less than $118 \mathrm{~mm}$.

\section{Mid clavicular circumference Right clavicle}

The mid clavicular circumference of male right clavicles varies from $35-48 \mathrm{~mm}$. with a mean of $39 \mathrm{~mm}$ where as that of female ranges from $28-$ $36 \mathrm{~mm}$ with a mean of $31 \mathrm{~mm}$. No female clavicle in this series has been found to have length more than $36 \mathrm{~mm}$. Similarly no male clavicle has been found to have length less than $35 \mathrm{~mm}$.

\section{Left Clavicle}

The mid clavicular circumference of male left clavicles varies from $34-50 \mathrm{~mm}$. with a mean of $37 \mathrm{~mm}$ where as that of female ranges from $24-$ $35 \mathrm{~mm}$ with a mean of $31 \mathrm{~mm}$. No female clavicle in this series has been found to have length more than $35 \mathrm{~mm}$. Similarly no male clavicle has been found to have length less than $34 \mathrm{~mm}$. 


\section{JMSCR Vol||4||Issue ||06||Page 11162-11165||June}

Demarcating points from the above results calculated that is the measurement above which no female bone can be found and below which no male clavicle can be found. So, demarcating points for various parameters found in our studies are shown in table 1.

Table 1: Demarcating points for the length and mid clavicular circumference of right \& left clavicles of both sexes

\begin{tabular}{|l|l|l|l|l|}
\hline \multirow{3}{*}{ Sex } & \multicolumn{3}{|l|}{ Demarcating points } & \multicolumn{2}{l|}{ Mid clavicular circumference } \\
\cline { 2 - 5 } & Length & Left & Right & Left \\
\cline { 2 - 5 } & Right & $>143$ & $>36$ & $>35$ \\
\hline Male & $>145 \mathrm{~mm}$ & $<118$ & $<35$ & $<34$ \\
\hline Female & $<123 \mathrm{~mm}$ & \multicolumn{2}{|l}{} \\
\hline
\end{tabular}

\section{DISCUSSION}

Sex determination using human skeletal remains is one of the most important components in forensic identification and starting point of anthropologic researches. Previous studies have shown that various communities have different skeletal anthropometric parameters according to their race and $\operatorname{sex}^{(7)}$. Sex determination is the most significant information which can be obtained from bones. In previous studies, morphologic methods were mostly used to determine sex. However, metric measurements are preferred due to their easy repeatability, high accuracy and no requirement for special skills ${ }^{(8)}$.
Measurements of most human body bones indicated that men often have greater bone dimensions than women. This is applicable for the clavicle bone as well and different studies such as Thieme $^{(9)}$, Mc Cormick ${ }^{(10)}$, Luis Fructos ${ }^{(11)}$ and our study indicate that the length and mid clavicular circumference are larger in men comparing to women.

On comparing the measurable characters of clavicle of our region with with findings from different zones of India, it provide us information regarding their racial and sexual differences.

Table 2: Mean values of length of right \& left clavicles in different zones of India in $\mathrm{mm}$

\begin{tabular}{|l|l|l|l|l|}
\hline \multirow{2}{*}{ Zones } & \multicolumn{3}{l|}{ Male } & Female \\
\cline { 2 - 5 } & Right & Left & Right & Left \\
\hline Gujrat & 141 & 142 & 125 & 126 \\
\hline Amritsar & 145 & 147 & 130 & 129 \\
\hline Varanasi & 141 & 144 & 125 & 127 \\
\hline Patiala & 146 & 148 & 132 & 133 \\
\hline Chandigarh & 148 & 149 & 132 & 134 \\
\hline Present study & 138 & 140 & 120 & 123 \\
\hline
\end{tabular}

Table 3: Mean values of mid clavicular circumfernece of right \& left clavicles in different zones in India in $\mathrm{mm}$

\begin{tabular}{|l|l|l|l|l|}
\hline \multirow{3}{*}{ Zones } & Male & Female \\
\cline { 2 - 5 } & Right & Left & Right & Left \\
\hline Gujrat & 37 & 36 & 30 & 30 \\
\hline Amritsar & 36 & 35 & 29 & 29 \\
\hline Varanasi & 35 & 34 & 28 & 28 \\
\hline Patiala & 36 & 36 & 30 & 30 \\
\hline Chandigarh & 36 & 35 & 30 & 30 \\
\hline Present study & 39 & 37 & 31 & 31 \\
\hline
\end{tabular}


Average length of clavicle has been compared by Olivier $(1956)^{(12)}$. He found that the French left clavicle to be longer than the right. Similar results were obtained by Jit and Singh (1966) in Amritsar zone, Singh and Gongrade (1968) in Varanasi zone, Jit and Sahani (1983) in Chandigarh zone, and Kaur et al (1997) in Patiala zone.The present workers found that the left clavicle was longer than the right. Same result also we got in our study.This is due to the greater curvatures present in the right clavicle.

In the Gujrat zone best criterion for identification of sex was mid clavicular circumference for right clavicle and length for left clavicle in female. In Varanasi zone and Amritsar zone length was found to be better criterion for identification of female clavicles. In our study mid clavicular cicumference was found to be best criterion for identification of female bone.

\section{CONCLUSION}

The determination of sex from the clavicle has a great medicolegal significance to the toxicologists. The result of this study indicate that sex can be determined using clavicle dimensions with relatively high accuracy, if just clavicle bone is available due to explosion, plane crashes, mutilated bodies etc. It also helps the anthropologists in their study of evolution of mankind and migration of races. The knowledge of morphometric values is helpful to anthropological and forensic practice.

\section{REFERENCES}

1. Johnson D, Ellis H. Grey's Anatomy. $39^{\text {th }}$ edition. 2005:817-818

2. Khaleel N, Pillai J. Morphometry of clavicle. Journal of Pharma Sci and Res. 2014:6(2):112-114

3. Krogman W, Iscan M. Human skeleton in forensic medicine. $2^{\text {nd }}$ edition, Charles C, Thomas, Springfield, 1986

4. Ashish K, Gayatri, Anil R. Morphometric parameters and sex determination of clavicle in Telangana region. Journal of Dental and Medical Sciences. 2014:13:01-05

5. Terry RJ. The clavicle of the American Negro. American Journal of Physical Anthropology. 1932:16:351-380

6. Jit I, Singh S. The sexing of adult clavicles. Indian Journal of Medical Research. 1966:54:551-571

7. Slaus M, Tomicic Z. Discriminant function sexing of fragmentary and complete tibiae from medieval Croatian sites. Forensic Science Int. 2005:147:147-152.

8. Mitra Akhlagi, Behzad M. Sex determination using anthropometric dimensions of the clavicle in Iranian population. Journal of Forensic and Legal Medicine. 2012:19:381-385

9. Thieme FP, Schull WJ. Sex determination from the skeleton. Hum Biol. 1957:29:242-273.

10. Mc Cormick WF, Stewart JH. Sexing of human clavicle using length and circumference measurement. Am J Forensic Med Pathology. 1991:12:175181

11. Fructos LR. Determination of sex from the clavicle and scapula in a Guatemalan contemporary rural indigenous population. Am J Forensic Pathology. 2002:23(3):284-288

12. Patel JP, Shah SP. Sexing of the human adult clavicle in Gujrat zone. Gujrat Medical Journal. 2009:2;40-46 